\title{
ASPECTOS DA RELAÇÃO PESSOA-ANIMAL NA CONSERVAÇÃO DA FAUNA SILVESTRE AMAZÔNICA EM RISCO DE EXTINÇÃO
}

\author{
Wagner de Deus Mateus ${ }^{1}$ \\ Maria Inês Gasparetto Higuchi ${ }^{2}$
}

\begin{abstract}
RESUMO
O trabalho apresenta quais aspectos constituem a relação pessoa-animal na amazônia e seus desdobramento na conservação da fauna silvestre em risco de extinção. A pesquisa foi bibliográfica e campo, neste último utilizou-se a técnica de grupo focal. Os dados coletados foram discutidos mediante a técnica da Análise de Conteúdo. A pesquisa foi em quatro comunidades amazônicas. Verificou-se que as formas de percepção do mundo e consequentemente posicionamento sobre as espécies não-humanas coadunam-se aos tipos de relações construídas entre os seres vivos nos diversos contextos. As dimensões da coexistência entre humanos e a animais da fauna silvestre, constroem-se a medida que os conhecimentos sobre as mesmas são aprofundados.
\end{abstract}

Palavras-chave: espécie-bandeira, percepção, coexistência, caça

\section{ASPECTS OF THE HUMAN-ANIMAL RELATIONSHIP IN THE CONSERVATION OF AMAZONIAN WILDLIFE AT RISK OF EXTINCTION}

\begin{abstract}
The work presents which aspects constitute the person-animal relationship in the amazon and its unfolding in the conservation of the wild fauna in danger of extinction. The research was bibliographical and field, in the latter the focal group technique was used. The data collected were discussed using the Content Analysis technique. The research was carried out in four Amazonian communities. It has been found that the forms of perception of the world and consequently positioning on the non-human species are in line with the types of relations constructed between living beings in different contexts. The dimensions of coexistence between humans and animals of wild fauna are built up as knowledge about them is deepened.
\end{abstract}

Key-words: species-flag, perception, coexistence, hunting

\footnotetext{
${ }^{1}$ Doutor em Ciências do Ambiente e Sustentabilidade na Amazônia pela Universidade Federal do Amazonas. E-mail: wagnermthus@gmail.com

${ }^{2}$ Doutora em Antropologia Social - Brunel University of London (1999). Atualmente é pesquisadora titular do Instituto Nacional de Pesquisas da Amazônia, coordenando o Laboratório de Psicologia e Educação Ambiental. E-mail: higuchi.mig@gmail.com
} 


\section{INTRODUÇÃO}

O mundo globalizado afeta a forma como nos relacionamos com os demais seres vivos. Essa afirmação é corroborada por uma diversidade de estudos sobre a coexistência entre as espécies, discute-se como seres humanos estavam juntos, próximos ou na companhia de outros animais, antes mesmo do nomadismo e muito mais com a domesticação. De acordo com Morris (1990) as relações criadas entre as espécies, pela proximidade e coexistência, representavam uma forma de contrato animal, onde tanto humanos como não-humanos, estavam numa igualdade de percepção e interação com o ambiente.

A coexistência entre humanos e cães é um exemplo deste contrato. Essa relação com os cães domésticos do gênero Canis, atualmente "natural", é um caso do processo de aproximação mútua (MARCHESINI, 2011). A proximidade ocorreu mediante a domesticação, uma ação de controle reprodutivo e seleção artificial, operacionalizada a partir de determinados animais funcionais à espécie humana.

A preferência sobre determinados animais, se por um lado permitiu a aproximação, por outro criou uma lacuna com outras espécies, pois na visão utilitarista, não possuíam função na vida humana. Trata-se, portanto, de uma objetificação, precarização e discriminação das outras espécies, identificada como especismo (SINGER, 2010). A preferência por espécies em desfavor de outras é o reflexo de nossa estrutura social, as necessidades humanas, sejam elas alimentícias, estéticas, lazer, saúde, segurança e assim por diante (SINGER, 2010). Ressalta-se que essas formas de percepção e coexistência com os outros animais caminham em acordo com as lógicas de pensamento da época e lugar, logo, não são hegemônicos. No caso da lógica ocidental moderna vê-se o especismo, pois preconiza uma dicotomização do cultural/natural, social/ambiental, do humano e não-humano.

No entanto, há grupos humanos onde essas separações simplesmente não fazem sentido, seja pelo fato de não haver a separação, seja por isso não ser uma preocupação primeira (INGOLD, 2015). Dessa forma, a relação entre os seres vivos pode ser múltipla. Se em determinados lugares no mundo é comum alimentar-se de carne, seja bovina ou suína, existem outros locais, onde uns são considerados deuses, e outros são tratados como seres impuros 
ao consumo. Isso reforça o objetivo de analisar como a percepção humana de outros animais impacta na constituição das sociedades humanas.

A constituição referida perpassa categorias linguísticas humanas (DEMELLO, 2012), categorizando animais nas classes de estimação, pecuária, trabalho, casa, fazenda, laboratório, televisão, "selvagem", etc. A esse enigma linguístico, soma-se o senso comum de perceber o animal como o antagônico de humano, uma categoria naturalizada.

O entendimento do conceito/termo animal deve ser percebido a partir de seus constructos próprios, ou seja, o animal em si, aliado ao contexto em que se encontra, pois também se trata de uma construção sociocultural (DEMELLO, 2012; TAYLOR, 2013). Para Taylor (2013), na essência, o animal torna-se um termo guarda-chuva para tudo que simplesmente não é humano. Isso, no entanto, faz uma série de injustiças para as várias espécies que são subsumidas dentro deste termo "animal" e evita qualquer discussão de semelhanças e diferenças entre espécies. A criação epistêmica de animais, ou seja, a construção sociocultural deles em um nível de conhecimento, justifica as formas como as diversas populações humanas os representam, percebem e os tratam (TAYLOR, 2013).

O aprofundamento da discussão sobre a categoria animal, encaminhase para a noção de animalidade e humanidade (INGOLD, 1994). Ressalta-se que considerar a animalidade em oposição a humanidade é um traço marcante da tradição ocidental, tal como natureza e cultura, corpo e espírito, emoção e razão, e assim por diante. Para Ingold (1994, 1995, 2007), a cada geração existirá uma concepção de animalidade, pois utilizará como parâmetro, por exemplo, as deficiências ou ausências de atributos que apenas nós, os seres humanos, supostamente temos, como a linguagem, a racionalidade, o intelecto e a consciência moral.

A discussão da construção do animal, seja pela animalidade, enquanto condição de ser, ou pela ausência de humanidade, é no atual momento uma questão que não está restrita somente a antropologia ou a biologia. $\mathrm{O}$ animal na atualidade também pode ser encarado como condição, ou um lugar comum (DERRIDA, 2002), e isso nos move a pensar que antes de qualquer categoria, presença ou ausência de características, ele é um ser vivo, um ser senciente, 
ou seja, um ser que sente dor. Logo, o animal também pode ser inserido na discussão moral (SINGER, 2010; REGAN, 2004, 2006).

\section{FORMAS DE RELAÇÃO HUMANO-ANIMAL: CASOS AMAZÔNICOS}

O animal enquanto relação e construção sociocultural é característica do ambiente em que cada sociedade humana se encontra. No contexto amazônico, uma das formas de relação ou interação entre humanos e animais não-humanos representa um dispositivo cultural local, a caça (DESCOLA, 1998; MENEGALDO et al., 2013; VANDER VELDEN, 2017; VIEIRA e SHEPARD, 2017). Ao contrário da caça comercial, que representa um indicador de extinção de espécies (YOUNG et al., 2016), localmente, a caça representa uma fonte de obtenção de recursos alimentares, uma prática simbólica presente na constituição de estruturas cosmológica (VIEIRA e SHEPARD, 2017). Portanto, a caça, por exemplo, representa um tema fecundo para compreender a relação pessoa-animal, em particular na antropologia.

Para Descola (1998, p.25) a relação com os animais na Amazônia, significa perceber que "diferentemente do dualismo moderno que distribui humanos e não-humanos em dois domínios ontológicos mais ou menos estanques, as cosmologias amazônicas estabelecem uma diferença de grau, não de natureza". Deste modo, o aspecto da interação entre humanos e demais seres encontra-se estruturado dentro de um quadrangular ontológico construído a partir das relações entre características fundamentadas na interioridade (aspectos relativos a subjetividade, consciência, perceptos, intencionalidade) e fisicalidade (relativas às substâncias que nos compõe, forma exterior, processos fisiológicos, expressões tangíveis do ser) (DESCOLA, 1996, 2009, 2012, 2013, 2016).

Os quatro tipos de ontologias, analógica, naturalista, animista e totemista, são sistemas de distribuição de propriedades entre objetos existentes no mundo, e fornecem pontos chave para formas sociocósmicas de associação e concepção de humanos e não-humanos. A analógica refere-se tanto a interioridade e a fisicalidade percebidas em descontinuidade, ou seja, diferentes entre si. Nela todas as entidades do mundo são fragmentadas numa multiplicidade de essências, formas e substâncias separadas por pequenos intervalos, frequentemente organizadas numa escala gradual. A ontologia 
naturalista ressalta o aspecto de domínio humano sobre a natureza. Nesta, a cultura moderna ocidental apresenta-se por uma descontinuidade na interioridade e semelhanças físicas entre humano e os demais seres vivos. $O$ homem é percebido como um ente especial no mundo (DESCOLA, 2012).

$\mathrm{Na}$ ontologia animista, os humanos atribuem a (certos) não-humanos uma humanidade idêntica à sua. Supõem-se haver uma continuidade cultural originária, diversificada a partir da descontinuidade material, ou seja, uma diversidade de corpos. Os corpos são concebidos como 'forma', um conjunto de afetos, ornamentos e equipamentos biológicos de cada espécie (DESCOLA, 2012). Os seres que aqui vagam, sejam eles seres humanos, animais e plantas partilham de uma mesma "alma" (interioridade continua ou semelhante) com os humanos, no entanto há uma diferença física entre humanos e não-humanos. Nesse processo dialógico é possível estabelecer relações sociais, até mesmo de parentesco com os animais.

A dimensão ontológica do totemismo, tanto fisicalidade quanto interioridade são percebidas como contínuas entre os seres vivos. A relação entre humano e não-humano se dá por uma afinidade de qualidades entre todos os seres que compartilham a mesma origem, através de um mesmo ser prototípico (DESCOLA, 2012). O totemismo é cosmogênico, pois seus atributos são pré-existentes à natureza e à cultura, logo seus coletivos são internamente homogêneos, com características naturais e culturais (DESCOLA, 2012, 2013).

Das quatro ontologias o animismo é um aspecto comum em populações habitantes do Norte e no Sul das Américas, assim como na região da Sibéria e em algumas partes do sudoeste asiático. Nesses locais as pessoas consideram plantas, animais e outros elementos de seus ambientes físicos possuidores de subjetividade e estabelecem com estas entidades todo tipo de relação pessoal, seja de amizade, troca, sedução ou hostilidade (DESCOLA, 2006). Além do aspecto animista como visão de mundo presente na região amazônica, destaca-se também, a questão perspectivista ou multinaturalista, enquanto teoria epistemológica (VIVEIROS DE CASTRO, 1996).

Viveiros de Castro (1996) discute que no perspectivismo, vê-se com frequência a noção de roupa ser utilizada para diferenciação entre as espécies. Nesse caso, os seres vivos, os animais, compartilhariam do mesmo tipo de interioridade, porém, o mundo que cada uma destas entidades percebe e usa é 
diferente, pois seus corpos são distintos (VIVEIROS DE CASTRO, 1996). Com isso, Viveiros de Castro (1996, 1998, 2004) discute o "perspectivismo" como uma teoria utilizada para fazer referência a característica posicional de algumas cosmologias ameríndias.

Nestas cosmologias, os humanos, em condições normais, percebem humanos como humanos, animais como animais e espíritos (quando os percebem) como espíritos; os animais (predadores) e os espíritos percebem os humanos como animais (presas), enquanto os animais (de caça) percebem os humanos como espíritos ou como animais (predadores). Logo, a relação entre animismo e perspectivismo, se dá pelo desdobramento do segundo em relação ao primeiro, pois de acordo com Viveiros de Castro (1996, p.117), “o perspectivismo é um corolário etno-epistemológico do animismo".

Se por um lado, o animismo na sua forma padrão, entende que os humanos citam que não-humanos se percebem como humanos pelo fato de compartilharem de uma interioridade similar, por outro, ou ao lado, o perspectivismo adiciona um dispositivo posicional. Nisso, implica-se que os humanos ao dizerem que alguns não-humanos não percebem os humanos como humanos, mas sim como não-humanos, logo, se humanos se percebem com uma forma humana e veem os não-humanos com uma forma inumana, então não-humanos que se percebem com uma forma humana devem ver os humanos com uma forma inumana.

Para não cair em armadilhas do relativismo e universalismo, a cosmologia ameríndia não sugere que qualquer animal (apenas animais de caça) possa vir a ser como (relativismo) uma pessoa, mas sim que um determinado animal, nesse caso, uma onça, como exemplifica o autor, seja percebida (perspectivismo) como um humano, pessoa ou gente. No perspectivismo, "os animais são gente, ou se veem como pessoas [...] que a forma manifesta de cada espécie é um mero envelope (uma "roupa") a esconder uma forma interna humana, normalmente visível apenas aos olhos da própria espécie" (VIVEIROS DE CASTRO, 1996, p.117). Aceita-se, portanto, que "o ponto de vista cria o sujeito; será sujeito quem se encontrar ativado ou 'agenciado' pelo ponto de vista” (VIVEIROS DE CASTRO, 1996, p.126).

Deste modo, para o perspectivismo o que de fato há é apenas uma cultura, ao passo que a natureza é múltipla, um mesmo mundo, múltiplos 
olhares. Deste modo, o autor discute que "a condição original comum aos humanos e animais não é a animalidade, mas sim a humanidade" (VIVEIROS DE CASTRO, 2015, p.60). Para Viveiros de Castro (2015), outrora os animais e outros seres cósmicos foram humanos, mas ainda continuam a sê-lo, mesmo que de uma forma não evidente para nós. Essa condição levanta a seguinte questão, se todos os modos do existente são humanos para si mesmo, nenhum é humano para nenhum outro (VIVEIROS DE CASTRO, 2015).

\section{ESTUDOS HUMANO-ANIMAL: CAMPO EMERGENTE}

Esses pressupostos teóricos servem de input para pensar a relação entre humanos e não humanos na Amazônia. No entanto, não exclui outras vertentes teóricas de aliar-se a essa problemática, dessa forma, o trabalho evidencia os Estudo Humano-Animal (EHA) entendida como um campo interdisciplinar. Nele, se discute os espaços ocupados por animais não humanos nos mundos sociais e culturais humanos, assim como as interações que os seres humanos têm com eles (DEMELLO, 2012). Os EHA enfatizam aspectos complexos das relações entre humanos e animais, indo além dos estudos comportamentais centrados nos animais, tal como a etologia, zoologia, primatologia e outras. O seu escopo é explorar as formas em que a vida dos outros animais se cruzam com as sociedades humanas (SHAPIRO, 1990, 2002; SHAPIRO e DEMELLO, 2010; HERZOG, 2010; MACIEL, 2011; DEMELLO, 2012; BIRKE e HOCKENHULL, 2012; WALDAU, 2013; TAYLOR, 2013; MARVIN e MCHUGH, 2014; MARCHAND e VANDER VELDEN, 2017).

Os EHA têm sua origem nos estudos culturais, e possui relação com a Antrozoologia, Estudos Animais, Direito/Ética animal e Estudos Animais Críticos (SHAPIRO, 2002; SHAPIRO e DEMELLO, 2010; WALDAU, 2013; HURN, 2010, 2015; DEMELLO, 2012). De acordo com Maciel (2011), os EHA se tratam de uma forma de movimento social, que surgiu a partir do ativismo animal de meado dos anos 1970, e envolveu ativistas dos direitos civis, feministas, ecologistas, pacifistas, anarquistas e filósofos.

A identificação da relação entre humanos e animais não humanos no trabalho, se deu pela adoção do termo pessoa-animal, um binômio representativo. Nele, o termo "pessoa" é entendido como um ser histórico, cultural e cognitivo, representado pela espécie Homo sapiens, e o termo 
animal, um lugar genérico (DERRIDA, 2002), representado pelas espécies da fauna silvestre. Entenda-se fauna silvestre como espécies nativas, migratórias e quaisquer outras, aquáticas ou terrestres, que tenham todo ou parte de seu ciclo de vida ocorrendo dentro dos limites do território brasileiro, ou águas jurisdicionais brasileiras (BRASIL, 1998).

De acordo com discussões do EHA, o silvestre também é aquela espécie fora do controle humano ou das comunidades humanas e, portanto, de vida livre (HERDA-RAPP \& GOEDEKE, 2005; BEATSON, 2011; WALDAU, 2013). São seres que vivem independente ou autonomamente, e possuem liberdade reprodutiva (YARBROUGH, 2015), e em determinados espaços, são parcial e limitadamente incorporados a vida humana (CUDWORTH, 2011).

O silvestre não representa o oposto de doméstico, mas sim um momento histórico. O doméstico sugere um processo e condição de controle humano, de trazer animais para os seres humanos, ou permitir que eles se aproximem e tenham uma coexistência próxima. Atualmente os animais silvestres são percebidos nas sociedades industriais como uma categoria que vale a pena salvar, pois fazem parte do estilo moderno da vida humana. DeMello (2012) cita que esse contexto demonstra um entendimento egocêntrico de superioridade, pois se antes, enquanto povo atrasados, nossa relação com eles era de caça-presa, agora evoluídos, está em mudança para protetor-fauna silvestre.

Em locais como a Amazônia, discutir a fauna silvestre também é pensar o doméstico e feral. Este último, refere-se aos domésticos que passam a ocupar ambientes naturais, como fragmentos florestais urbano. Nesse sentido a pesquisa enfatiza as relações entre humanos e animais silvestres em comunidades amazônicas. Não se descarta a presença dos animais domésticos, haja vista a coexistência dos humanos com estes, seja os usualmente percebidos, ou os transformados em domésticos. Esse contexto surge numa estrutura relacional onde há "animais demais", ou seja, os animais são sujeitos onipresentes no imaginário, tanto nos espaços indígenas como os não-indígenas (ERIKSON, 2012).

A pesquisa se insere na problemática da conservação de duas espécies da fauna amazônica em risco de extinção, a saber: gavião-real (Harpia harpyja) e o tracajá (Podocnemis unifilis). O gavião-real na classificação da União 
Internacional para a Conservação da Natureza (IUCN) (2016), encontra-se como "Near threatened" (NT) ou quase ameaçada, já para o ICMBio (2014), a espécie está "Vulnerável" (VU). No caso do tracajá, a espécie é classificada como Vulnerável (Vulnerable) (IUCN, 2016). Respectivamente, as espécies possuem ações conservacionistas desenvolvidas pelo Programa de Conservação do Gavião-Real (PCGR) desenvolvido pelo Instituto Nacional de Pesquisa da Amazônia (INPA), e o Projeto Pé-de-Pincha (PPP), organizado pela Universidade Federal do Amazonas (UFAM).

Deste modo, discute-se quais aspectos constituem a relação pessoaanimal e como isso desdobra-se na conservação da fauna silvestre amazônica em risco de extinção. Enfatiza-se o papel das espécies-bandeira como mediadores/incentivadores a conservação de outras espécies animais locais, conflitos com a fauna silvestre e quais os fatores estão presentes na constituição da vida em comunidade.

\section{MATERIAL E MÉTODOS}

A área de estudo foi distribuída em quatro comunidades amazônicas: Santa Clara do Quebrinha (2o39'22.76"'S e 56o31'35.36"O) e São Sebastião do Quebra (2041'57.28"S e 56032'04.54"O) no município de Parintins (AM) e Tucumanduba (2053'09.85"S e 57002'54.89"O) e Piraí (3o04'26.84'S e 57009'.49"O) no município de Barreirinha (AM). A escolha dos participantes foi baseada na acessibilidade e conveniência, independente de gênero, religião ou etnia, mas que fosse da comunidade e que estivessem participando ou que já tivessem participado do projeto.

A pesquisa foi organizada em dois momentos: a pesquisa bibliográfica e a pesquisa de campo. No primeiro momento, foi evidenciada a emergência dos EHA enquanto eixo discursivo aos estudos sobre conservação. Na pesquisa de campo foram realizadas discussões utilizando grupos focais (GF), orientados por um roteiro de temas. As discussões foram audiogravada e transcritas. A opção pelo GF se deu pelo fato das questões presentes favorecem as dimensões simbólicas e pragmáticas, abarcando as complexidades as relações entre humanos e animais na região amazônica (TRAD, 2009). As dificuldades encontradas foram da ordem de invisibilidade dos discursos e tempos de 
discussão, mas o contorno, se deu pela discussão de temas de interesses comuns e que representassem a realidade local.

Os GFs enfatizaram os participantes e o projeto como unidade sobre a qual se manifesta o conhecimento e relação com a espécie foco e por extensão a relação constituída com outros animais da fauna local. Foram realizados quatro GFs, um por comunidade pesquisada, no período de dezembro de 2016 a março de 2017. Seguindo as orientações da literatura, os grupos foram formados por 6 pessoas cada, e um tempo médio de 30 minutos por localidade. Ressalta-se que as análises dos dados enfatizaram uma integração entre questões de conversas informais prévias individuais e as constituintes do GFs voltadas a vida com os animais nas localidades. Tais questões evidenciam dimensões da coexistência entre humanos e fauna silvestre local em questão, a saber: a espécie-bandeira, os conflitos e a vida em comunidade

As questões presentes nessa técnica enfatizaram as formas de tratamento dadas as espécies silvestres locais como um todo, e não apenas relativo ao tracajá ou o gavião-real. Devido ao fato da pesquisa envolver seres humanos, seguiu-se todas as normas éticas previstas na Resolução 196/96 (BRASIL, 1996). O trabalho foi enviado e aprovado no Comitê de Ética em Pesquisa (CEP) - CAAE: 55135916.5.0000.5020 sob o parecer número 1.589.187.

As análises dos dados enfatizaram a identificação dos temas ou temáticas (BARDIN, 2016) e respectivas subcategorias relacionadas aos temas mais amplos. Com isso, o processo de análise contemplou dois momentos: análise específica de cada grupo e análise cumulativa e comparativa do conjunto de grupos realizados, pois o objetivo deste processo foi identificar tendências e padrões de respostas associadas com o tema de estudo (TRAD, 2009), ou seja, a coexistência com animais silvestres.

\section{DE ESPÉCIES-BANDEIRA À FAUNA SILVESTRE LOCAL}

As análises demonstraram como as formas de tratamento e conhecimento da conservação das duas espécies-bandeiras, tem relação ou desdobram-se em comportamento e atitudes para conservar outras espécies da fauna local, seja ela doméstica ou silvestre. Trata-se, portanto, de uma questão comportamental, conservacionista ou não, por associação ou 
transposição, já que o ponto de partida são espécies-bandeira. A espéciebandeira é em si, uma ação estratégica e, têm efeitos/influência no domínio cultural humano (CLUCAS et al., 2008; CARO, 2010). Esses efeitos surgem em virtude de suas conexões com outras entidades (instituições, públicos, estados) ou mesmo ideias, mitos, valores que interagem para trazer benefícios mais amplos aos sistemas ecológicos envolvidos (JEPSON e BARUA, 2015).

Nos GFs, questionou-se como o tratamento dado ao tracajá e ao gaviãoreal servem de molde para outros comportamentos humanos em relação a vida com outras espécies. A questão central não foi analisar se as referidas espécies funcionam ou não como espécie-bandeira, isso aparece em segundo plano. O fato é saber se as formas como foram orientados a tratar as duas espécies podem ser utilizadas ou transpostas as demais espécies da fauna local.

Essa discussão é pouco evidenciada em estudos acerca das espécies bandeiras, pois como destaca Jepson e Barua (2015), a mesma concentra-se em dois grandes temas: critérios e avaliação. O primeiro refere-se aos critérios de seleção de espécies para promover como bandeira (BOWEN-JONES e ENTWISTLE, 2002; BARUA et al., 2012). Já a segunda aprofunda-se em descrever as diferentes formas em que as espécies-bandeira foram utilizadas, e analisa sua eficácia em diferentes papéis de conservação (CLUCAS et al., 2008; HOME et al., 2009; VERISSIMO et al., 2014).

Dentre os entrevistados dos dois programas, apenas dois participantes, no caso do tracajá, não consideraram que as formas de tratar a espéciebandeira tenham contribuído para desvelar outros comportamentos para com as demais espécies locais. Para eles, a forma de tratar, ou conservar, ficou restrita a espécie. Os demais participantes perceberam que os modos de tratamento orientados à ave e ao quelônio serviram de alguma forma como parâmetro ou exemplo para agir ou se relacionar com outras espécies animais na comunidade.

A percepção desse desdobramento da conservação da espéciebandeira para outros seres, agrupam percepções distintas, mas não excludentes. Para o primeiro grupo (23 entrevistados), verifica-se a possibilidade de realizar a transposição dos tratamentos entre espécies, já o segundo grupo (13 entrevistados), percebe essa possibilidade atrelada a 
condições comportamentais. O primeiro grupo ao visualizar a possiblidade de transporem as formas de tratamento entre as espécies, evidenciam o aspecto biofílico, ou seja, a capacidade, não inata, mas construída ao longo das experiências, de criar conexões com a ambiente natural e seus constituintes (SIMAIKA e SAMWAYS, 2010).

Nesse primeiro grupo a transposição, também pode ser entendida como uma forma de conservação por associação, e deste modo caracteriza-se por diversos objetivos, tais como: a) necessidades do gavião (2 entrevistados), b) evitar a extinção das espécies (2 entrevistados), c) estreitar a relação pessoaanimal (3 entrevistados), d) todos merecem o mesmo tratamento (8 entrevistados), e) manutenção da caça/alimento (8 entrevistados). O fato de todas as espécies merecerem o mesmo tratamento dado aos gaviões e tracajás, evidencia a questão da igualdade entre as espécies, rechaçando o especismo:

"Rapaz, acho que todas as espécies devem ser bem tratadas. Devem ser tratadas com carinho, porque senão acaba e depois só vai ter história. $E$ inclusive não sei quantas espécies já foram extintas pelo homem, que já saíram mesmo, que não existe mais. Só vai estar no livro de história" (Comunidade Quebra).

Essa importância de tratamento, ou conservação similar as espéciesbandeiras, é percebida como uma forma de evitar a extinção da fauna. $\mathrm{Na}$ manutenção da caça, a oportunidade de generalização do modus operandi do manejo e conservação é uma solução a questão da obtenção de alimento. Nisto, a necessidade de tratar as demais espécies ou conservá-las tal como foi orientado pelos programas, tendo como objetivo a manutenção dos recursos alimentares também ocorre no segundo grupo, mas diferente do primeiro, aqui, isso é permeado por condições.

Nesse sentido, a transposição da forma do tratamento é uma possibilidade, mas está atrelado a dois aspectos, o primeiro refere-se, a) espécie ou tipo de animal (7 entrevistados), e o segundo, é referente às b) atitudes e comportamentos das pessoas (6 entrevistados), e aqui entram fatores educativos, socioculturais entre outros, como verifica-se nas falas:

\footnotetext{
"Acho que só os animais, aqueles proibidos, os que não tem que matar, a caça não, porque é alimento, mais não pra destruir. Podemos tratar os de caça, mas não temos que acabar também. Podemos tratar todos, pode sim, porque o do mato, é melhor ainda, agora não pode é a onça, mais difícil de criar ela" (Comunidade Quebra).
} 
O relato acima se refere ao primeiro grupo, que condiciona a transposição do tratamento de conservar as demais espécies, tal como ocorre com as espécies-bandeira, a uma diferenciação interna, relativa a forma de relação pessoa-animal. Nela, a conservação é possível se for uma espécie com valor nutritivo, mas deve ser repensada ou mesmo evitada, quando se trata de animais que trazem alguma forma de perigo, tal como a onça ou cobras.

As espécies que podem, nas falas dos moradores, serem conservadas, tal como ocorrido com o gavião e tracajá, são em sua maioria identificadas como animais de caça, ou seja, aqueles que possuem função nutricional. Essas percepções foram corroboradas, ao serem instigados a citarem quais espécies também deveriam ter ações de manejo e conservação. A lista inclui as seguintes espécies por comunidades/programa: no PCGR, aves, veado, paca, cutia, caititu, anta, macacos, tatu, jabuti, calango e capivara; no PPP, paca, cutia, capivara, anta, caititu, jabuti, peixes, tatu, peixe-boi, veado e tartaruga (Tabela 1).

Tabela 1. Espécies para serem conservadas organizadas por nome popular, cientifico, frequência de citações e estado de conservação segundo IUCN (2016) e ICMBio (2014).

\begin{tabular}{cccc}
\hline Espécie citada & Frequência de & $\begin{array}{c}\text { Estado de } \\
\text { Citações }\end{array}$ & Conservação \\
\hline Nome popular & Nome científico & 10 & Pouco preocupante \\
Paca & Cuniculus paca & 9 & Pouco preocupante \\
Cutia & Dasyprocta aguti & & Vulnerável \\
Anta & Tapirus terrestris & & Pouco preocupante \\
Caititu & Pecari tajacu & 6 & Pouco preocupante \\
Capivara & Hydrochoerus hydrochaeris & 4 & Vulnerável \\
Jacu & Penelope ochrogaster & 4 & Pouco preocupante \\
Papagaio-comum & Amazona aestiva & 4 & Pouco preocupante \\
Jabuti-piranga & Chelonoidis carbonaria & 3 & Vulnerável \\
Tatu-canastra & Priodontes maximus & 3 & Pouco preocupante \\
Guaribas & Alouatta guariba & 2 & Dados insuficientes \\
Pirarucu & Arapaima gigas & 2 & Dados insuficientes \\
Veado & Mazama americana & 2 & Pouco preocupante \\
Arara-vermelha & Ara chloropterus & 1 & Pouco preocupante \\
Mutum-cavalo & Pauxi tuberosa & 1 & Vulnerável \\
Peixe-boi & Trichechus inunguis & 1 & Quase ameaçada \\
Periquito & Nannopsittaca dachilleae & 1 & Vulnerável \\
Tartaruga & Podocnemis expansa & 1 & Pouco preocupante \\
Tucano & Ramphastos toco & 1 &
\end{tabular}

Fonte: Próprio autor

As cinco espécies mais citadas representam mamíferos, de pequeno e grande porte. Destas, apenas a anta e o caititu encontram-se em perigo de 
extinção, classificada como vulnerável de acordo com a Red List da IUCN e Lista do ICMBio (2014), as demais são consideradas pouco preocupante. Os mamíferos representam uma classe animal que possui um apelo emblemático, estético preferido para ser um símbolo ou marca de instituições ambientais (CLUCAS et al., 2008; HOME et al., 2009; SMITH et al., 2012). Outro aspecto relacionado aos mamíferos e as aves, é o apelo carismático, que os qualifica para serem espécies-bandeira, localmente apropriadas (BOWEN-JONES e ENTWISTLE, 2002). O que uni as duas classes de animais é o fato da defaunação agir diretamente em suas populações (DIRZO et al., 2014).

Entende-se que as diretrizes ou critérios técnicos para uma espécie animal, ser considerada ou torna-se uma espécies-bandeira, perpassam pelo carisma, ser um símbolo simples e instantaneamente reconhecível que evoca uma resposta emocional positiva entre os membros do público-alvo (CARO, 2010; VAUGHAN, 2010). As espécies citadas acima, além de serem representativas como animais a serem conservados, seja como forma de manter e aumentar a população, assim como evitar a sua extinção nas localidades, representam também um cenário onde haverá uma facilidade de acesso a esses animais, enquanto caça, tal como ocorria em épocas passadas.

Deste modo, a paca, cutia e a anta são espécies que deveriam ter ações de conservação nas localidades pesquisadas, pois representam fontes nutritivas de fácil acesso, mas que na atualidade são escassas. Por outro lado, as diferenças entre as comunidades, também se refletem na identificação das espécies, pois nas ribeirinhas, além dos mamíferos, tem-se também a questão do pescado, já nas de terra firme, a escolha volta-se as aves. Portanto, o ecossistema é um fator estruturante para identificar possíveis espécies a serem conservadas.

\subsection{Conservação e antropomorfização}

Para Beatson (2011), a conservação dos animais silvestres é uma atitude moderna, formada ao longo do último século, desencadeada por uma consciência conservacionista, adquirida principalmente pela preocupação com a fauna carismática, seja pela admiração pública ou simpatia por ela. Um aspecto a ser destacado quanto as espécies carismáticas, é seu caráter 
estético antropomórfico. Os animais "escolhidos" para serem bandeira da conservação possuem atributos físicos e comportamentais homogêneos, sendo próximos, tolerados ou apreciados pelo ser humano. Ao passo que animais que não apresentam tais condições são rechaçados da visão e círculo humano.

O filtro humano que atribui às determinadas espécies animais um conjunto de práticas e comportamentos ditos humanos, caracteriza-se como 0 processo de antropomorfização (EPLEY et al., 2008; KULICK, 2009; THOMAS, 2010). Trata-se, portanto, de uma ferramenta conservacionista para atrair a atenção humana, evidenciando determinadas características da espécie em questão, seja o comportamento, a estético ou semelhança antropomórfica (CHAN, 2012; ROOT-BERNSTEIN et al., 2013).

A antropomorfização é um processo pelo qual animais não-humanos, como os de estimação (pets), são identificados como se fossem pessoas, pois vivem na casa de humanos, onde são tratados como membros de suas famílias. Como exemplos cotidianos, tem-se os cães e os gatos, em sua maioria animais domesticados, mas também podem ser extrapolados para animais de criação, assim como os silvestres. Logo, a domesticação é uma tentativa de aproximar ou inserir animais ao cotidiano humano.

Nos casos em questão, os mamíferos e aves possuem esses atributos, logo, isso os classificariam como candidatos a espécie-bandeira. No entanto, necessita-se de estudos para pontuar quais os motivos não levam esses animais à visibilidade humana, uma vez que assim como o quelônio e a ave, essas espécies também se encontram em risco de extinção na região.

\section{CONFLITOS E CONSERVAÇÃO DA FAUNA SILVESTRE: LINHA TÊNUE}

Como apontado acima, a possibilidade de transpor as atitudes e comportamentos conservacionistas de uma espécie-bandeira à outra, pode ocorrer de forma livre, mas também por condições. Uma destas condições é relativa ao tipo de comportamento animal, ou seja, depende se a espécie traz ou não perigo ou benefício à vida dos humanos. Nisto, revela-se a questão de conflitos entre as espécies. Estudos mostram que essa problemática representa uma dimensão relacional entre as espécies, na qual fatores como questões sociais, econômicas, ambientais e territoriais têm profunda relevância 
(WOODROFFE et al., 2005; HERDA-RAPP e GOEDEKE, 2005; MANFREDO, 2008; MARCHAND, 2013).

De acordo com Manfredo (2008), os motivos que levam aos conflitos dependem de variáveis locais. Mas em geral, são decorrentes da ocupação humana, em especial pela expansão dos assentamentos humanos, pois são impulsionados pelas pressões populacionais, crescimento econômico e pela crescente demanda global por recursos naturais. Como resultado, há invasão, destruição ou fragmentação dos hábitats, o que potencializa os confrontos. $E$ à medida que as pessoas invadem os habitats naturais, o contato entre pessoas e animais selvagens cresce. Dessa forma, Madden (2004) cita que o conflito se caracteriza quando as necessidades e o comportamento da vida selvagem têm um impacto negativo nos objetivos humanos ou quando os objetivos humanos têm um impacto negativo na vida selvagem.

Para Marchand (2013), a dimensão dos conflitos é formada por duas interfaces. A primeira refere-se aos impactos negativos da fauna nas sociedades humanas, ou seja, os ataques às plantações agrícolas ou florestais por herbívoros/frutívoros, assim como ataques de carnívoros aos animais de fazenda ou mesmo as pessoas. Por outro lado, há impactos negativos sobre a vida selvagem, quando as medidas que afetam a integridade física do animal estão em voga. Nesse sentido, as soluções mais utilizadas pelas populares locais para prevenir, reduzir ou resolver conflitos seriam envenenar, ferir ou matar de forma seletiva ou aleatoriamente espécies problemáticas (MARCHAND, 2013).

Historicamente, as pessoas responderam a essas ameaças matando a vida selvagem sempre que possível, o que levou à ameaça de muitas espécies endêmicas (WOODROFFE et al., 2005). Portanto, há a necessidade urgente de conservar essas espécies, mas para isso, Woodroffe et al. (2005), cita a prevalência da coexistência de pessoas e animais silvestres ameaçados de extinção. Herda-Rapp e Goedeke (2005), apresenta duas dimensões para o conflito humano-fauna em meio a conservação. A primeira refere-se aos atritos entre humanos e animais, seja por recurso alimentar, território ou encontros negativos, já a segunda refere-se aos conflitos entre humanos voltados a conservação das espécies e pessoas, grupos ou comunidades contra a ação. 
Por fim, Marchand (2013) considera que a natureza dos conflitos pode ser direto e indireto. Essas interações negativas são consideradas diretas no sentido de que essas diferentes espécies destroem o capital humano (superfícies agrícolas, casas) e / ou danificam a integridade física de seres humanos e animais sob sua proteção. Existem também interações indiretas. Este é o caso quando a vida selvagem é acusada (justa ou indevidamente) ataca os recursos naturais utilizados por grupos humanos (peixe, jogo, fruta e sementes) ou interrompe sua colheita.

No caso em questão, as duas formas coexistem, não necessariamente com as espécies-bandeira nas localidades estudas, mas com determinadas espécies locais como verificado nas falas dos comunitários:

"Sim, aqui tem, a cobra, as vezes a onça. O mais perigo é a onça, mas aqui é mais difícil, mas a cobra. Sim, apareceu um bando de porco a gente matou uns dois e o resto foi embora, mas foi só pra comida mesmo" (Comunidade Quebrinha).

"Tem bastante, ainda mas nesse tempo chuvoso, como a cobra, no rio tem o jacaré, aqui tem bastante jacaré, jacaré grande, jacaré açú"(Comunidade Pirai).

Nas comunidades de conservação do gavião-real, os conflitos são em sua maioria diretos, envolvendo onças-pintadas e cobras. Nas voltadas ao tracajá, além das duas espécies, acrescenta-se também os jacarés e pequenos insetos, como aranhas e mosquitos. Há também nos dois contextos, conflitos indiretos com porco-do-mato ou caititu, já que quando entram em contato com os humanos, eles podem destruir os roçados dos moradores. Dessas espécies, a onça (Panthera onca) é a que mais encontra-se em perigo de extinção (ICMBio, 2014).

As onças e outros felinos, assim como as cobras historicamente são sujeitos envolvidos em conflitos com grupos humanos (WOODROFFE et al., 2005; MARCHINI e CRAWSHAW JR, 2015; HERZOG, 2010; MANFREDO, 2008). No primeiro caso, as onças sofrem com a expansão da ocupação humana, isso gera, os chamados encontros indesejados (MARCHINI, 2017), onde os felinos vão ao encontro de animais de criações, assim como a entrada nas áreas das comunidades. Já no caso das cobras, além das formas de ataques que possam ocorrer, provenientes de espécies peçonhentas ou não, também existem os aspectos subjetivos.

Esses aspectos têm relação com a tradição cristã, pois representa o mal (DEMELLO, 2012), também pressentimentos negativos (HERDA-RAPP e GOEDEKE, 2005). Pesa também sobre essas espécies sentimento 
diametralmente opostos a biofilia, ou seja, a biofobia, que representa os medos relacionados a riscos naturais ou a formas de vida como cobras e aranhas, que podem vir a ameaçarem os seres humano (MANFREDO, 2008; HERZOG, 2010).

Mesmo o foco do presente trabalho não sendo o processo de escolhas das espécies-bandeira, assim como a identificação de conflitos humano-fauna, percebe-se que nos dois casos, os processos educativos podem ter um papel relevantes, tanto para aprofundar o conhecimento sobre determinado animal, assim como desmitificar ações e comportamentos. Trata-se, portanto, de conhecer as funções e comportamentos das espécie-bandeira que se busca conservar e o motivo para esta ação, mas também discutir com os comunitários, por exemplo, que a onça, possui uma baixa frequência de ataques aos seres humanos.

As ações que favorecem a divulgação dessas informações perpassam, nos dois casos, tanto as palestras, reuniões, oficinas, debates são processos que ajudam nas discussões dos referidos temas, sejam na escola ou fora dela. Para Woodroffe et al. (2005) existem quatro principais estratégias e ações políticas mitigadoras aos conflitos, a saber: soluções técnicas, incentivos econômicos, proteção legal e envolvimento comunitário.

As soluções técnicas referem-se, por exemplo, as práticas do manejo quando se pretende aumentar a população de determinada espécie. Os incentivos econômicos incluem compensação, pagamentos de desempenho e utilização e consumo de animais selvagens para gerar receita. Já a proteção legal como força do estado, tem a função de criar sentimentos de privação de direito, o que pode trazer consequências negativas. E por fim, o envolvimento comunitário é chave para iniciar as ações de mitigação, pois são as pessoas locais que estão enfrentando os custos de vida ao lado da vida selvagem e, portanto, são aqueles que mais provavelmente matam animais selvagens, legalmente ou ilegalmente.

\section{A COEXISTÊNCIA COM OUTROS ANIMAIS NAS COMUNIDADES}

Nesta seção, as discussões pautam-se nas relações de coexistência entre moradores das comunidades e a fauna silvestre. A despeito de enfatizar a coexistência, Woodroffe et al. (2005) cita ser uma ação necessária para 
mitigar os problemas dos conflitos entre humanos e fauna, os quais tem crescido ultimamente, e levando a extinção inúmeras espécies da biodiversidade. Mas para além dos conflitos, a coexistência em questão é aquela oriunda das relações, encontros e convívios entre distintas espécies que ocupam o mesmo ambiente. Trata-se de saber dos entrecruzamentos das vidas dos animais nas referidas comunidades, pois como cita Keck (2015), estudar o animal é pensa-lo em quanto sujeito relacional.

Dessa forma, para dinamizar as respostas, os GFs, foram montados de forma a discutir como eles se refletem sobre sua relação com a fauna local. Nesse sentido, as discussões pautaram-se em dois momentos, a saber: animais na comunidade e o futuro dos animais. Para cada tema, duas questões-chave.

\title{
5.1 Animais na comunidade
}

A evidencia deste tema, surge para analisar quais e como as relações são construídas entre humanos e animais nas comunidades. Para tanto, as questões enfatizaram primeiramente aspectos históricos da existência da fauna nas comunidades e regiões, antes da ocupação humana, e como isso se processa na atualidade. Na sequência, os questionamentos pautaram-se sobre a diversidade dos tipos de animais, em que se pese, domésticos, criação e silvestres. Nas discussões, os moradores destacaram aspectos semelhantes acerca da fauna local, como verifica-se nas falas:

\begin{abstract}
"Essa região aqui do Quebra era uma área muito farta de caça, de espécies de animais, vinham de lá para cá caçar, essa região aqui ela sempre foi muito farta, talvez porque aqui é uma área de fronteira e ser pouco habitado" (Comunidade Quebra).
\end{abstract}

No relato acima, evidencia-se que a presença humana foi um entrave a manutenção da fauna, tal como era antes, principalmente como consequência da prática da caça, seja comercial ou para usufruto próprio. No entanto, o aspecto da coexistência enquanto convívio, de certa forma, equilibrado, está presente na visão de pessoas que são oriundas da própria região. Nesse caso, seriam os outros, que pressionam e contribuem a extinção das espécies. Não é possível ser taxativo e afirmar que os grupos que ali vivem, são caçadores, pois de acordo com DeMello (2012), se fossem grupos caçadores coletores, os animais seriam unicamente caçados e comidos, mas não, já que nas comunidades eles são criados e controlados. 
O que há é uma forma de coexistência, que hora teme um animal e noutra, busca amansá-lo, domesticá-lo, como mostram as falas:

\begin{abstract}
"Muitas vezes os próprios silvestres nós tentamos domesticar, o nosso povo tem uma cultura acho que muito apegada, muito ligada na natureza e quando ele encontra por ali um filho de porco do mato ou filho de veado ou de uma paca ou de uma cutia ou de uma capivara, ele quer trazer pra casa, para criar, para transformar aquele silvestre em doméstico, nós sabemos que é uma realidade diferente, mais acontece muito dentro da nossa comunidade" (Comunidade do Pirai).
\end{abstract}

Como discutido anteriormente, entende-se que a domesticação é um dos marcos na diferenciação da forma como humano passa a se relacionar com animais e plantas. No entanto, esse processo na Amazônia vê-se atrelado à caça, uma característica direta dos povos indígenas. Os animais domesticados em decorrência da caça se apresentam na figura dos xerimbabos, ou seja, animais de estimação indígenas, ou também animais familiares, ou que se tornaram familiarizados (DESCOLA, 1998; INGOLD, 2000; ERIKSON, 2013). Há, portanto, uma memória biocultural que orienta ou mesmo dá subsidio a manutenção dessa prática de domesticação, que em última instancia é uma forma de coexistir na região.

De acordo com Toledo e Barreira-Bassols (2008) noção de memória biocultural se fundamenta na noção de memória da espécie humana que supõe três dimensões: genética, linguística e cognitiva. Trata-se de uma inter-relação entre a história da humanidade com a história da natureza, oferecendo mediante a terceira dimensão a possibilidade de compreender, avaliar e valorar a experiência histórica em questão.

\title{
5.20 futuro dos animais
}

Se na história clássica a domesticação serviu como forma de libertar ou potencializar características e habilidades humanas, na Amazônia esse processo, constitui-se como uma habilidade em si. A habilidade de domesticar como forma de subsidiar a coexistência de outras formas de animais nas comunidades, pois como cita o morador, "o homem é capaz de domar todas as espécies de animal" (Comunidade Quebra). Esse processo é facilitado pelas ações de manejo e conservação, que para DeMello (2012), são invenções modernas da humanidade, considerada uma estratégia de manutenção da vida silvestre. 
A conservação da fauna como uma relação humana moderna nos encaminha para discutir como esse tema surgi para refletir e projetar o futuro das espécies, não apenas das espécies-bandeiras. Dessa forma, de início os moradores foram questionados sobre as consequências de não haver preocupação em conservar a fauna, e por fim, como seria a vida humana sem a presença dos outros animais. Questionados sobre o cenário da finitude caso não houvesse preocupação em conservar os animais, os moradores divergiram, como mostram as falas:

\footnotetext{
"Se tivesse de acabar mesmo, já tinha acabado, porque, olha que não é de hoje que si caça, as vezes matam um, dois, mas sempre tem, e só não mais matam porque não tem perto, porque eles ficaram com medo também. Acaba não acaba, fica difícil" (Comunidade do Quebrinha).

"Com certeza vão desaparecer assim na região, sei que também os culpados somos nós mesmos, se nós não tivermos o controle, hoje também em dia está crescendo muito a agropecuária na nossa região, como o desmatamento, tudo isso vai afetando os animais mesmo né, vai refletir nas nossas vidas mesmo mais tarde" (Comunidade do Tucumanduba).
}

A finitude da fauna é percebida nas falas, mesmo que de forma distinta. $\mathrm{Na}$ primeira, tem-se a visão de que não pode acabar, mas ficar raro encontrar os animais, representa a descrença nos processos de extinção evidenciados em diversas partes do planeta (GALETTI e DIRZO, 2013; DIRZO et al., 2014; YOUNG et al., 2016). Por outro lado, na outra comunidade, a visão da defaunação como consequência do descaso com a conservação é visível. $\mathrm{E}$ como causa, são apontadas as ações antrópicas diretas como a caça, e indireta como o desmatamento. Esses aspectos são condicionantes a época do Antropoceno (STEFFEN et al., 2011; STEFFEN et al., 2015).

A hipótese da extinção total da fauna, enquanto hipótese, reverbera-se apenas enquanto uma construção escatológica, ou seja, cenários apocalípticos (DANOWSKI e VIVEIROS DE CASTRO, 2014). No caso específico, a escatologia projetada no questionamento era se os humanos conseguiriam viver sem a presença, convívio, existência, ou companhia dos outros animais. Trata-se, portanto, de levar as últimas consequências os desdobramentos do antropoceno, ou como cita Aparício (2017), lapidar a excepcionalidade humana. Nesse sentido, os moradores desconhecem ou não acreditam em a possibilidade dos humanos viverem sem animais, como mostram em suas falas: 


\begin{abstract}
Eu acho muito difícil, muito difícil até porque nós estamos tão adaptados, por exemplo aqui em casa nós temos porco, galinha, pato, carneiro, cachorro e muitos outros e tem muito mais além, tem gente que tem uma cutia, tem paca, tem veado, tem porco do mato, caititu, queixada, as vezes alguém tem um macaco, tem papagaio, periquito e aqui os próprios de casa os passarinhos, eles vêm e entram na gaveta da mesa, lá se reproduzem, se reproduzem aqui na varanda, na própria casa é palco de reprodução, aqui nas plantas, então vamos dizer a gente convive diretamente com esses animais" (Comunidade do Pirai).
\end{abstract}

Os motivos que os levam a acreditar não ser possível um mundo sem os outros animais, é fato de estarem acostumados com os mesmos, sejam eles domésticos ou silvestres. Na fala, vê-se aspectos da dependência mútua, como por exemplo, o cão que protege a casa e familiares de indivíduos estranhos. E por outro lado, tem-se a função nutritiva que os mesmos possuem nas suas vidas, no caso dos animais de caça. Esses aspectos da coexistência fomentam a necessidade da vida humana na companhia dos animais (SERPELL, 1996; LESTEL, 2002; THOMAS, 2010; DEMELLO, 2012).

A verificação dessa necessidade e mesmo dependência das outras espécies, é entendida como uma relação "naturalizada", pois já estariam adaptados aos animais, sejam em grau ou quantidade, haja vista que a Amazônia é megadiversa em mamíferos (427 espécies), aves (1.300 espécies), répteis (378 espécies), anfíbios (427 espécies) e peixes de água doce ( 3.500 espécies) (SILVA et al., 2005; KRITSCH, 2009; WWF, 2014). O fato se serem percebido animais demais (ERIKSON, 2013) na região, torna as visualizações das hipóteses escatológicas de finitude quase inexistentes. Mesmo assim, no mundo globalizado e interconectado, ações mitigadoras são cada mais necessárias.

\title{
CONSIDERAÇÕES FINAIS
}

As diversas formas de percepção do mundo e consequentemente de posicionamento frente outras espécies não-humanas no universo mostram a necessidade de entender como as relações entre os seres ocorrem nos inúmeros contextos, sejam eles urbanos ou rurais. Nesse sentido, baseando-se nos EHA, a priori, compreende que na relação com os humanos, o animal, surge como uma construção sociocultural. 
Com isso entende-se que as dimensões da coexistência entre humanos e a animais da fauna silvestre, constroem-se a medida que os conhecimentos sobre as mesmas são aprofundados. Pois dessa forma, é possível perceber a importância das espécies animais, não apenas das caças, mas também as conflituosas. Por fim, entende-se que a prática da caça, antes da conservação, é a dimensão que impera e nas comunidades pesquisadas, pois o foco da relação entre humanos e a animais é a obtenção de alimentos.

\section{REFERÊNCIAS}

APARÍCIO, M. Um mundo sem animais, ou a rota da nossa desconexão. Campos - Revista de Antropologia, v.17, n.1, p.65-77, 2017.

BARDIN, L. Análise de conteúdo. Lisboa: Edições Setenta, 2016.

BARUA, M.; et al. Defining Flagship Uses is Critical for Flagship Selection: A Critique of the IUCN Climate Change Flagship Fleet. Ambio, v.40, n.4, p.431435, 2011.

BEATSON, P. Mapping Human Animal Relations. In: TAYLOR, N.; SIGNAL, T. Theorizing animals: re-thinking humanimal relations, p.21-58, 2003.

BIRKE, L.; HOCKENHULL, J. Crossing boundaries: investigating humananimal relationships. Leiden, Boston: Brill, 2012.

BOWEN-JONES, E.; ENTWISTLE, A. Identifying appropriate flagship species: the importance of culture and local contexts. Oryx, v.36, n.2, p.189-195, 2002.

BRASIL. Ministério da Saúde. Conselho Nacional de Saúde. Comissão Nacional de Ética em Pesquisa. Resolução CNS 196/96, 1996.

BRASIL. Lei de Crimes Ambientais. Lei № 9.605, de 12 de Fevereiro de 1998. Disponível em: http://www.planalto.gov.br/ccivil 03/leis/L9605.htm

CARO, T. M. Conservation by Proxy: Indicator, umbrella, keystone, flagship, and other surrogate Species. Island Press: Washington, Covelo, London, 2010.

CLUCAS, B.; et al. Flagship species on covers of US conservation and nature magazines. Biodivers., Conserv., v.17, p.1517-1528, 2008.

CHAN, A. A. Y. Anthropomorphism as a conservation tool. Biodivers., Conserv., v.21, p.1889-1892, 2012.

CUDWORTH, E. Social lives with other animals: tales of sex, death and love. New York, NY: Palgrave MacMillan, 2011. 
DANOWSKI, D.; VIVEIROS DE CASTRO, E. Há mundo por vir? Ensaios sobre os medos e os fins. Florianópolis: Cultura e Barbárie, 2014.

DERRIDA, J. O animal que logo sou. São Paulo: Editora UNESP, 2002.

DESCOLA, P. Constructing natures: symbolic ecology and social practice. In: DESCOLA, P.; PÁLSSON, G. (eds). Nature and society: anthropological perspectives. Routledge, London, p.82-102, 1996.

DESCOLA, P. Estrutura ou Sentimento: a relação com o animal na Amazônia. MANA, v.4, n.1, p.23-45, 1998.

DESCOLA, P. Beyond Nature and Culture. Proceedings of the British Academy, v.139, p.137-155, 2006.

DESCOLA, P. Humannatures. Social Anthropology, v.17, n.2, p.145-157, 2009.

DESCOLA, P. Más allá de naturaleza y cultura. - 1a ed. - Buenos Aires: Amorrortu, 2012.

DESCOLA, P. Beyond Nature and Culture. The University of Chicago Press, 2013.

DESCOLA, P._Outras naturezas, outras culturas. São Paulo, Editora 34, 2016.

DEMELLO, M. Animal and Society: an introduction to human-animal studies. New York: Columbia University Press, 2012.

DIRZO, R.; et al.. Defaunation no Antropoceno. Science, v.345, n.6195, p.401-406, 2014.

EPLEY, N.; et al. When we need a human: motivational determinants of anthropomorphism. Social Cognition, v.26, n.2, p.143-155, 2008.

ERIKSON, P. Animais demais... os xerimbabos no espaço doméstico matis (Amazonas). Anuário Antropológico, v.2, p.15-32, 2012.

GALETTI, M.; DIRZO, R. Ecological and evolutionary consequences of living in a defaunated world. Biological Conservation, v.163, n.6, 2013.

HERZOG, H. Some We Love, Some We Hate, Some We Eat. Why It's So Hard to Think Straight About Animals. HarperCollins e-books, EPub Edition, 2010. 275p. 
HOME, R.; et al. Selection criteria for flagship species by conservation organizations. Environmental Conservation, Foundation for Environmental Conservation, p.1-10, 2009.

HURN, S. What's in a name? Anthrozoology, human-animal studies, animal studies or...? Anthropology Today, v.26, n.3, p.27-28, 2010.

HURN, S. Anthrozoology: an important subfield in Anthropology. In: HARTUNG, G.; HERRGEN, M. (Hrsg.) Interdisziplinäre Anthropologie. Fachmedien Wiesbaden: Springer, p.79-88, 2015.

HERDA-RAPP, A.; GOEDEKE, T. L. Mad about wildlife: looking at social conflict over wildlife. Leiden, Boston: Brill, 2005.

INGOLD, T. Become Persons: consciousness and sociality in human evolution. Cultural Dynamics, v.4, n.3, 1991.

INGOLD, T. What is an animal? London: Routledge, 1994.

INGOLD, T. From Trust To Domination: An Alternative History Of HumanAnimal Relations. In: MANNING, A.; SERPELL, J. (eds.) Animals and human society: changing perspectives. New Fetter Lane, London: Routledge, p.122, 1994b.

INGOLD, T. Humanidade e animalidade. Rev. bras. Ci. Soc., v.10, n.28, 1995.

INGOLD, T. The Perception of the Environment. Essays on livelihood, dwelling and skill. London and New York: Routledge, 2000.

INGOLD, T. A evolução da sociedade. In: FABIAN, A. C. (Org.). Evolução: sociedade, ciência e universo. Bauru: Edusc, p.107-131, 2003.

INGOLD, T. Beyond Biology and Culture: the meaning of evolution in a relational world. Social Anthropology, v.12, n.2, p.209-221, 2004.

INGOLD, T. Rethinking the Animate, Re-Animating Thought. ETHNOS, v.71. n.1, p.9-20, 2006.

INGOLD, T. Introdução. O que é um animal? Antropolítica, n.22, p.29-150, 2007.

INGOLD, T. Da transmissão de representações à educação da atenção. Educação, v.33, n.1, p.6-25, 2010.

INGOLD, T. Estar vivo: ensaios sobre movimento, conhecimento e descrição. Tradução: Fábio Creder. - Petropolis, RJ: Vozes, 2015.

INTERNATIONAL UNION FOR CONSERVATION OF NATURE (IUCN). Bird Life International. Harpia harpyja. The IUCN Red List of Threatened Species, 2016. 
INTERNATIONAL UNION FOR CONSERVATION OF NATURE (IUCN). Relatório Planeta Vivo 2014: América Latina passa por grande perda de biodiversidade, mas busca soluções para reverter cenário.

INSTITUTO CHICO MENDES DE CONSERVAÇÃO DA BIODIVERSIDADE (ICMBio). Portaria No 444 e 445, de 17 de Dezembro de 2014b. Lista de Animais em Extinção.

JEPSON, P.; BARUA, M. A Theory of Flagship Species Action. Conservat., Soc., v.13, p.95-104, 2015.

KECK, F. As relações homens/animais em Lévi-Strauss. R@u - Revista de Antropologia da UFSCar, v.7, n.1, p.97-107, 2015.

KRITSCH, R. The Amazon's flora and fauna. AMAZON Initiative. WWF. February 2009.

KULICK, D. Animais gordos e a dissolução da fronteira entre as espécies. Mana, v.15, n.2, 2009.

LESTEL, D. As origens animais da cultura. Paris: Flammarion, Lisboa: Instituto Piaget, 2001.

MACIEL, M. E. (org.). Pensar/escrever o animal: ensaios de zoopoética e biopolítica. Florianópolis: Editora da UFSC, 2011, 422p.

MANFREDO, M. J. Who Cares About Wildlife? Social Science Concepts for Exploring Human-Wildlife Relationships and Conservation Issues. Springer, 2008.

MARVIN, G.; MCHUGH, S. Routledge handbook of human-animal studies. Oxon, New York: Routledge, 2014.

MADDEN, F. Creating coexistence between humans and wildlife global perspectives and local efforts to adress human wildlife conflicts. Human Dimensions of Wildlife, v.9, p.247-257, 2004.

MARCHAND, G.; VANDER VELDEN, F. F. (Org.) Olhares cruzados sobre as relações entre seres humanos e animais silvestres na Amazônia (Brasil, Guiana Francesa). 1. ed. Manaus: EDUA, 2017. v. 1. 319p.

MARCHAND, G. Les conflits hommes/animaux sauvages sous le regard de la geographie. Carnets de géographes, v.5, 2013.

MARCHESINI, R. Umanitra Lupo e cane. II Manifesto, Cultura \& Vision, Domenica, Apr., 2011.

MARCHINI, S.; et al. Human-Wildlife Conflicts in Brazil: A Fast-Growing Issue. Journal Human Dimensions of Wildlife, p.20, n.4, 2015. 
MARCHINI, S. Dimensões humanas dos conflitos humano-fauna: a onçapintada na fronteira de ocupação da Amazônia. In: MARCHAND, G.; VANDER VELDEN, F. F. (Org.) Olhares cruzados sobre as relações entre seres humanos e animais silvestres na Amazônia (Brasil, Guiana Francesa). 1. ed. Manaus: EDUA, p.121-138, 2017.

MENEGALDO, L. R.; et al. Interações socioculturais com a fauna silvestre em uma unidade de conservação na Amazônia: relações de gênero e geração. Bol. Mus. Para. Emílio Goeldi. Cienc. Hum., v.8, n.1, p.129-151, 2013.

MORRIS, D. O contrato animal. Record, 1990.

REGAN, T. The case for animal rigths. Los Angeles: University California Press: 2004.

REGAN, T. Jaulas vazias: encarando o desafio dos direitos animais. Porto Alegre: Lugano, 2006.

ROOT-BERNSTEIN, M.; et al. Anthropomorphized species as tools for conservation: utility beyond prosocial, intelligent and suffering species. Biodiversity and Conservation, 2013.

SERPELL, J. A. In the company of animals: a study of human animal relationships. Cambridge: Cambridge University, 1996.

SHAPIRO, K.; DEMELLO, M. The State of Human-Animal Studies. Society \& Animals Journal, v.18, n.3, 2010.

SHAPIRO, K. The Human Science Study of Nonhuman Animals. Phenomenology + Pedagogy, v.8, 1990.

SHAPIRO, K. Introduction. The state of Human-Animal Studies: Solid, at the margin! Society \& Animals, v.10, p.331-337, 2002.

SILVA, J. M. C. da S.; et al. The Fate of the Amazonian Areas of Endemism. Conservation Biology, v.19, n.3, 689-694, 2005.

SINGER, P. Libertação Animal. São Paulo: Editora WMF Martins Fontes, 2010.

SIMAIKA, J. P.; SAMWAYS, M. J. Biophilia as a Universal Ethic for Conserving Biodiversity. Conservation Biology, v.24, p.903-906, 2010. 
SMITH, R. J.; et al. Identifying Cinderella species: uncovering mammals with conservation flagship appeal. Conservation Letters, v.5, n.3, p.205-212, 2012.

STEFFEN, W.; et al. The Anthropocene: conceptual and historical perspectives. Phil. Trans. R. Soc. A, v.369, p.842-867, 2011.

STEFFEN, W.; et al. The trajectory of the Anthropocene: The Great Acceleration. The Anthropocene Review, p.1-18, 2015.

TAYLOR, J. Intergenerational justice: a useful perspective for heritage conservation. CeROAr, 2013.

TAYLOR, N. Humans, animals, and society: an introduction to human-animal studies. Brooklyn, NY: Lantern Books, 2013. 133p.

THOMAS, K. O homem e o mundo natural: mudanças de atitudes em relação as plantas e aos animais (1500-1800). São Paulo: Companhia das Letras, 2010.

TOLEDO, V. M.; BARREIRA BASSOLS, N. La memória biocultural: la importância ecológica de las sabidurias tradicionales. Barcelona: Icaria Editorial, 2008.

TRAD, L. A. B. Grupos focais: conceitos, procedimentos e reflexões baseadas em experiências com o uso da técnica em pesquisas de saúde. Physis Revista de Saúde Coletiva, v.19, n.3, p.777-796, 2009.

VAUGHAN, P. Flagship species create Pride. In: SODHI, N. S.; EHRLICH, P. R. Conservation for all. Oxford: Oxford University Press, p.223-224, 2010.

VANDER VELDEN, F. F. Fazendo animais sabidos: interações naturalculturais nas práticas cinegéticas Karitiana (Rondônia). In: MARCHAND, G.; VANDER VELDEN, F. F. (Org.) Olhares cruzados sobre as relações entre seres humanos e animais silvestres na Amazônia (Brasil, Guiana Francesa). 1. ed. Manaus: EDUA, 2017. v.1, p.65-84.

VERÍSSIMO, D.; et al. Using a Systematic Approach to Select Flagship Species for Bird Conservation. Conservation Biology, v.28, n.1, p.269-277, 2014.

VIEIRA, M. A. R. de M.; SHEPARD, G. H. "A anta tem muita ciência": racionalidade ecológica e ritual da caça entre ribeirinhos amazônicos. In: MARCHAND, G.; VANDER VELDEN, F. F. (Org.) Olhares cruzados sobre as relações entre seres humanos e animais silvestres na Amazônia (Brasil, Guiana Francesa). 1. ed. Manaus: EDUA, 2017. v.1, p.41-64.

VIVEIROS DE CASTRO, E. Os pronomes cosmológicos e o perspectivismo ameríndio. Mana, v.2, n.2, 1996. 
VIVEIROS DE CASTRO, E. Cosmological Deixis and Amerindian Perspectivism. The Journal of the Royal Anthropological Institute, v.4, n.3, p.469-488, 1998.

VIVEIROS DE CASTRO, E. O Nativo Relativo. Mana, v.8, n.1, p.113-148, 2002.

VIVEIROS DE CASTRO, E. Perspectivismo e multinaturalismo na América indígena. O que nos faz pensar, n.18, 2004.

VIVEIROS DE CASTRO, E. A natureza em pessoa: sobre outras práticas de conhecimento. Encontro "Visões do Rio Babel, Conversas sobre o futuro da bacia do Rio Negro, Instituto Socioambiental, Fundação Vitória Amazônica, Manaus, Mai., 2007.

VIVEIROS DE CASTRO, E. O medo dos outros. Revista de Antropologia, v.54, n.2, p.885-917, 2011.

VIVEIROS DE CASTRO, E. A inconstância da alma selvagem e outros ensaios de antropologia. Cosac \&Naify, São Paulo, 2013.

VIVEIROS DE CASTRO, E. Metafisicas canibais: elementos para uma antropologia pós-estrutural. São Paulo, Cosac Naify, 1aㅡ ed., 2015.

WALDAU, P. Animal Studies - An Introduction. Okford: Oxford University Press, 2013. 379p.

WOODROFFE, R.; et al. People and Wildlife Conflict or Coexistence? Cambridge: Cambridge University Press, 2005.

YARBROUGH, A. Species, race, and culture in the space of wildlife Management. In: COLLARD, R.-C.; GILLESPIE, K. Critical animal geographies. Oxon, RN, New York, NY: Routledge Human-Animal Studies Series, p.293-343, 2015.

YOUNG, H. S.; et al. Patterns, Causes, and Consequences of Anthropocene Defaunation. Annual Review of Ecology, Evolution, and Systematics, v.47, p.333-358, 2016. 